\title{
Mulheres de Érico
}

Flávio Aguiar*

\author{
* Universidade de São Paulo
}


Elas eram o chão firme em que os heróis pisavam

Floriano Cambará

(Érico Veríssimo, O arquipélago, p. 864)

Já se tornou lugar comum dizer que as personagens femininas de Érico Veríssimo, em particular em se tratando de $O$ tempo e o vento ${ }^{1}$, são muito mais interessantes do que os personagens masculinos. Isto não só porque dêem impressão de mais consistência, mais tenacidade e de maior complexidade psicológica. Também se lê aí a maior simpatia e empatia que o escritor revelou por e com elas, maior identificação com seus valores, e mesmo, vez por outra, maior empenho na sua elaboração. É rico era um autêntico liberal, não destes que assim se intitulam, como é comum na vida brasileira, enquanto se acobertam debaixo do autoritarismo de plantão, quando não o instigam a se tornar pior do que é. Tinha horror à violência. Consolidara seu destino de escritor na vigência do Estado Novo, por cujos desmandos e atrocidades não tinha a menor simpatia, como se pode ver pelas reflexões de F loriano, o alter-ego do escritor, ao final de $O$ arqui pélago, terceira parte de $O$ tempo e o vento. Fora contemporâneo da Guerra Civil Espanhola, do Nazi-fascismo e da ascensão do E stalinismo, inclusive dentro da esquerda brasileira. Vira a Segunda Guerra M undial e as hecatombes 
de Hiroshima e Nagasaki. A Segunda Guerra, era comum dizer-se então, fora a guerra que viera para acabar com todas as guerras. Mal terminada ela, multiplicavam-se as guerras de libertação nacional na África e na Ásia, sendo a maior delas a R evolução Chinesa. Iniciava-se a Guerra Fria e multiplicavam-se também as intervenções norte-americanas nas Américas, para garantir a sua hegemonia. Enfim, o escritor e pensador É rico sentia-se perplexo diante de um mundo onde a violência parecia não ter fim. Sinal desta sua preocupação é o fato de, em meio a O tempo e o vento ter escrito México, livro de viagem, e Noi te, livro sobre a despersonalização na metrópole e na modernidade; e logo depois ter escrito $O$ senhor embaixador, que se abre para a A mérica Latina, e O prisi oneiro, diretamente sobre o tema da guerra e calcado no Vietnã. Planejado desde a década de 30, formulado pela primeira vez mais ou menos claramente no final de O resto é silêncio, de 1943, quando o escritor Tônio Santiago imagina uma saga que conte a história riograndense, durante um concerto no Teatro São Pedro, em Porto Alegre, O tempo e o vento é publicado entre 1949 e 1962. Além de ser um inventário da história riograndense e de da integração da província ao B rasil, a trilogia é ta mbém uma reflexão sobre o problema contemporâneo (de então e de hoje) da violência. A guerra, ou as guerras aparecem, mais de uma vez, como traço marcante e peculiar da história da província; são guerras de fronteira, de invasões, e guerras civis, com brutalidades, degolas, massacres, assassinatos a sangue frio cujo horror rivaliza com a bravura às vezes descrita dos atos de um ou outro personagem. A presença da guerra e da violência leva o escritor F loriano a formular, nos seus Cadernos de pauta simples, uma teoria sobre o horror antigo e o horror moderno, aquele fantasmático, à la Edgar Poe, ou cru, como nas degolas, e este despersonalizado, frio, eficiente, matando com uma eficiência despudorada e aterradora². Por isto a saga de É rico é também uma reflexão e uma metáfora do mundo moderno. E o mundo aparentemente arcaico de Cambarás e Amarais, e das outras rivalidades que se sucedem permanece como uma sombra, distante, mas sombra, da violência do século $X X$. Pode-se dizer portanto que É rico vê a violência, a barbárie, como elemento ameaçador da civilização. Mas a vê como elemento ameaçador desde dentro. E ele se pergunta, então, sobre qual o lado civilizado, ou civilizatório, da civilização. Aí entram em cena as suas mulheres. É o que se pretende examinar através de alguns casos de O tempo e o vento.

A este propósito há interessante tese de Maria das Graças Vila da Silva, O horror antigo e o horror moderno em $\mathrm{O}$ Tempo e o Vento e Noite de Érico Veríssi mo, sob orientação da Profa. Cleusa Rios Pinheiro Passos, do Departamento de Teoria Literária e Literatura Comparada da F FLCH/USP, defendida em outubro de 1998. 
Antonio Candido já disse em duas oportunidades ${ }^{3}$ que É rico é um analista preferencialmente de grupos, não das insondáveis profundezas individuais. Isto fá-lo um comparatista, e um criador de galerias humanas. Estas galerias se distendem, muito ao gosto do escritor, que tem aí um de seus temas (no sentido musical) favoritos, pelo tempo. Assim a família Terra-Cambará, principal núcleo articulador e por isso mesmo principal objeto do romance, constitui-se por um suceder de presenças em épocas e planos diversos. Mas também se articula como uma enorme rede de relações comparadas de corações e caracteres que pode ser olhada de um golpe só, como se o enredo de romance tão grande pudesse ser congelado e visto também como uma simultaneidade. Outra não é a intenção manifesta do autor (entre outras intenções, é claro), ao compor o seu romance como uma sucessão de planos temporais intercalados por uma vasta ampliação espacial e temporal - da técnica do contraponto.

Pode-se dizer assim que o Dr. Rodrigo Cambará, para ainda se falar dos homens, sucede, mas está face à face com seu homônimo, o Capitão, marido de sua bisavó B ibiana. As ousadias desabridas deste, o seu pendor para aventuras amorosas escandalosas e nem sempre de comportamento muito ortodoxo (como a de sair de Santa Fé com a alemã Helga Kunz na garupa do cavalo à vista de todos, quando já era casado com B ibiana), se refletem nas ousadias e aventuras daquele, sempre em busca de uma revolução que o redima e da mulher do próximo ou da próxima mulher de modo também espalhafatoso (como no caso da também germânica Toni Weber, em O Retrato). O Capitão faz o que faz, de modo desempenado. O Doutor, ao se defrontar com a gravidez de Toni, se acovarda, coisa que a leva ao suicídio. M as aquilo que no caso do Capitão Rodrigo era um estilo natural de vida e desempeno de macho algo selvagem mas simpático, no Doutor se transforma na construção de uma carapaça retórica de comportamento, que o arrasta na direção de uma vertiginosa ascensão política, e num desejo irrefreável de afirmação sexual: não pode ver uma fêmea sem querer afirmar a sua macheza. O que no Capitão era pendor para a sedução, no Doutor vira frenesi. Algo da espontaneidade do Capitão sobrevive na rude coragem de Toríbio. Mas só se pusermos o Capitão e o D outor lado a lado, ou frente a frente, encurvand o a linha do tempo, é que se poderá ter a dimensão das transformações morais por que passam os Cambarás - e, por extensão, o Rio G rande, sob o olhar crítico de Érico. O Capitão era rude e tinha algo de bagual em seu comportamento; mas era de fato livre. $\mathrm{O}$ Doutor casa seus desejos de afirmação com refinamentos de roupas e vinhos eu- 
ropeus; mas é um prisioneiro da culpa. O primeiro morre trespassado por uma bala, ao assaltar a casa dos rivais políticos e sexuais, pois B ento Amaral disputara B ibiana com ele. O Doutor morre em sua própria casa, vitimado por um enfarte: é o primeiro Cambará a morrer na própria cama. A modernidade se instalou, com seus impasses e limites. A morte de Toríbio, numa espelunca, cortado na virilha por uma faquinha de sapateiro, mas aind a com tempo de castrar com suas próprias mãos seu assassino, é, de certo modo, também uma paródia cruel da morte do Capitão.

No caso das mulheres, o caso é mais complexo, pois de fato elas são mais complexas que seus rivais e amantes masculinos. Dois grandes pólos masculinos articulam o mundo romanesco, e já foram citados: os dois R odrigos, campeadores de mundos diversos, um da pampa desabrida, e o outro dos desabridos cartórios e cabarés do Rio, onde o leva a sua carreira política. Em torno desses dois pólos, articula-se um grande quadrilátero de mulheres, formado por B ibiana, Luzia Silva Cambará, Sonia Fraga, e Bibi.

\section{RODRIGO \\ BIBIANA LUZIA \\ RODRIGO \\ BIBI SONIA FRAGA}

Bibi é a filha estouvada do Doutor R odrigo, e tem o mesmo nome da trisavó. Sonia Fraga é a amante de Rodrigo que vem do R io para Santa Fé, quando ele está doente, apeado do poder, para escândalo de todos e escarmento de Flora, mulher do doutor. As outras duas dispensam apresentações. Diz-se mesmo que o conflito principal deO Conti nente não se dá entre Cambarás e A marais, farroupilhas e caramurus, pica-paus e maragatos, pela hegemonia em Santa Fé e no Estado, mas entre as duas pela posse do Sobrado. Bibi usa o mesmo nome da sua antepassada, com o desconto do final "ana", que remete à matriarca da família, sua fibra, que a velha B ibi-ana duplica; F loriano, o filho escritor do Doutor R odrigo, diz de Sônia $F$ raga que ela fá-lo lembrar-se da legendária Teiniaguá ( $O$ arqui pélago, “Caderno de Pauta Simples", p. 604) , a princesa moura transformada em lagarta, que era um epíteto pertencente à L uzia, dado pelo Dr. Winter (médico, intelectual, cujas hesitações e ambigüidades lembram, mutatis mutandis, as do próprio F loriano). Mas para se compreender as relações e o significado desse quadrilátero é preciso ir além dos nomes.

Comecemos pela dupla de teiniaguás. Além de compartilharem o parentesco com a lendária e sedutora princesa moura, ambas têm em comum o fato de virem do mesmo lugar: da Corte uma, da Capital da R epública a outra. Podemos 
dizer que são extensões da cidade grande, em seu círculo de tempo próprio, de seu cosmopolitismo, sofisticação, diante da pequenez vetusta de Santa F é. Luzia, como Sônia, causa estranheza no lugar onde chega, e ambas são, por assim dizer, "animalizadas". O Dr. Winter considera que ela tem "olhar de réptil". Se de um lado diz que ela é a Teiniaguá, de outro a considera como M elpômene, a musa da tragédia, evocando sua condição ambígua de homem do Ocidente civilizado em meio ao que vê como brutezas de Santa Fé. Sobre Sônia, vai dizer F loriano quase cem anos mais tarde (na página já referida antes) que ela é "um misto de ave pernilonga e felino" - também "animalizando-a", portanto. O "felino" lembra por oposição e complementaridade que Bibiana considerava Luzia uma "cadela". Diz ainda Floriano, aproximando a Sônia de sua visão da Luzia da visão de Winter, que naquela ele sente "algo de réptil". R esumindo: ambas são versões de um mesmo princípio mítico de desvio e sedução, ambas vêm da Cidade Grande e de perdição (uma espécie de babélica B abilônia, portanto), ambas são vistas do mesmo modo, ambas são sinais da perda de rumo que aflige os Cambarás - Bolívar e o Doutor Rodrigo. Ambas, de certo modo, se medem com a inteireza das mulheres do Sobrado.

Do lado das B ibis, a com o "ana" e a sem, o confronto é por paródia. A B ibi do século $X X$ nada tem de sua antepassada, a não ser as sílabas iniciais do nome desta. (No século XIX a ninguém ocorreria chamar a severa Bibiana de "Bibi"). É uma doudivanas, de cabeça perdida, teve marido, separou-se, vive com um casamento no Uruguai (como se fazia então) com um estróina que é simpático mas que aos olhos dos do Sobrado não vale nada. M ais ainda: não tem a menor capacidade de resistência diante da perdição que a família Cambará sofre ao deslocar-se para o Rio. Ao contrário; é, ela mesmo, uma "perdida", e desempenha um papel todo ao contrário de sua trisavó.

No episódio "Noite de A no Bom", o Doutor Rodrigo comemora o casamento do filho J ango com Sílvia. O Sobrado, antes vetusto, passa a concorrer com o Clube Comercial, pois arma-se ali um tablado de danças, capitaneado por um personagem efeminado que causa asco no Chefe do clã. Várias coisas acontecem nesta festa, entre elas o rompimento entre Toríbio e Rodrigo, porque este faz o elogio do Estado Novo, que aquele não suporta, além de considerar que os gaúchos que ficaram no Rio se perderam num mar de corrupção insuportável. Dali Toríbio, acompanhado de Floriano, sairá para a morte na espelunca da periferia de Santa F é. U ma das coisas notáveis que também acontece é que, ao tocar-se um frevo, Bibi dá um espetáculo, dançando aquele "exotismo" para os convivas do Sobrado, de modo frenético. Termina num gesto escandaloso, ofegante, deitada no chão, com os "braços e pernas abertos, o vestido sungado até a metade das coxas nuas" - "dando a impressão que esperava (assim pensou Rodrigo, num mal- 
estar, ao vê-la naquela posição), convidava mesmo, qualquer dos machos a atirarse em cima dela". O pai atarantado pela cena arranca a filha do chão e sopra-lhe ao ouvido: "Sua desavergonhada! Então isso é coisa que se faça?". ( O arqui pélago, p. 827). Parece que a própria Teiniaguá se apossou do corpo de B ibi - arrancado dela o sufixo "ana".

Há portanto, uma autêntica "invasão" do Sobrado, pelo menos do seu pátio, pelo espírito de perdição da cidade. Toríbio condensa a revolta que isso provoca, ao responder ao brinde do irmão, que saúda o "Chefe da N ação" e o "E stado Novo", com palavras definitivas:

“- Patife! Canalha! Cachorro! Capacho! Sabujo!".

Rodrigo diz que ele está bêbado. Toríbio retruca que ele está "podre por dentro". Antes que os dois se atraquem, os outros os separam, e a orquestra "ataca o Mamãe eu quero". ( O arqui pélago, p. 832).

Ao lado desta resistência de Toríbio, há outra, que se encarna no próprio Sobrado. Como ícones entronizados, três vultos assistem a festa das janelas do casarão. Numa, estão o Velho Aderbal, "fumand o seu crioulo", e sua mulher Dona L aurentina, pais de Flora. N outra, no andar de cima, a Velha Maria Valéria, quase cega (como Bibiana no fim da vida), que nada vê mas por vezes anda pelas peças da casa, e mesmo fora dela, com uma vela na mão. Se algo, ou alguém resiste ao desatado espírito da Teiniguá, este algo ou alguém está em ou é Maria Valéria, a “D inda" de Rodrigo. ( $O$ arqui pélago, p. 827). O quadro é interessante: a brasa do cigarro que Aderbal fuma evoca o lume da vela com que a "Dinda" anda, embora quase cega e depois cega mesmo. O gesto de M aria Valéria lembra a imagem, também mítica, do Negrinho do Pastoreio que, de vela na mão, é o santo da procura das coisas perdidas no R io G rande. Maria Valéria, com efeito, embora não pertença ao tronco principal da família, que passa por Ana-Pedro Terra-Bibiana-B olívarLicurgo-Rodrigo-Floriano (supostamente o autor do próprio romance), é quem retém consigo o espírito de resistência e sobriedade dos velhos tempos. Neste sentido, é a imagem dela, emoldurada pelo Sobrado, que se opõe à Festa que o invade. Mas é uma oposição no momento passiva, despojada de seu lume: talvez nada mais haja a procurar.

Aqui há um dos curiosos paralelismos de Érico, que trabalha com linhas encurvadas de tempo. A cena do frevo se passa na noite de A no N ovo de 1937 para 1938. Antes, ao final de O retrato, mas depois, na linha cronológica, isto é, em 1945 , quando o Doutor Rodrigo já está agonizando e os filhos e os pais não conseguem se entender, já víramos a Velha Maria Valéria, completamente cega, sair com F loriano para o pátio e acender uma vela para o N egrinho do Pastoreio. Para quê?

“É pr’aquela gente achar o que perdeu." (O retrato, p. 611), 
diz ela, apontando em direção ao Sobrado. Estão ambos ao pé de um marmeleiro-da-índia. E marmeleiros eram árvores da predileção de Bibiana. Deles ela lembrava (com outras árvores, naturalmente), quando lamentava que Aguinaldo Silva tinha tomado as terras e a casa de seu pai, para construir o Sobrado em cima. Foi ao pé de um marmeleiro-da-índia, plantado por Ana Terra, que B ibiana começou a ter "um particular" com o Dr. Winter sobre Luzia "não ser bem certa do juízo". Os momentos se misturam graças à técnica narrativa do contraponto; mas há mais: o tempo inflete, se recurva, e cria "blocos diacrônicos" de significado, onde o antes elucida o sentido do depois, e vice-versa. O leitor vê, antes, o fato posterior de 45: Maria Valéria acende a vela. Há uma perda, e uma esperança. Lê, depois, o fato anterior, de 37-38: Bibi dança o frevo, Maria Valéria está às escuras, na janela de cima, e Aderbal Quadros pita o crioulo, embaixo. O leitor percebe, aí, o quanto de impotência ia naquele gesto de Maria Valéria, de que ele já tinha conhecimento, acendendo a vela para o Negrinho. E de como tudo isso reata o laço com o sentimento de uma coisa perdida na linha do tempo, na linha contínua dos marmeleiros: a natureza, muda e indiferente, cerca o drama humano.

A comparação entre B ibi e Sônia F raga nos leva a idéia de que, se é verdade que no passado Bibiana dobrou a Teiniaguá e a venceu, na disputa pelo neto e pela posse do Sobrado, no fim de contas foi a sedutora que venceu: ela veio da Corte e em Santa Fé feneceu; mas depois a Capital da R epública, sucedânea da Corte, transviou os Cambarás, e eles se perderam, enquanto clã. Toríbio rompe, como já se viu, com o Doutor Rodrigo; e nada mais à parte um do outro do que os filhos do doutor, F loriano (que lembra F lora, a mãe), J ango, E duardo e Bibi, completamente estranhos entre si.

Isto poderia nos levar a ver em É rico um julgamento maniqueísta e nostálgico: o drama de O tempo e o vento seria o de que o mundo moderno, multifacetado, corrompeu o antigo, inteiriço; ou que o "B rasil" fez perder o "R io G rande". Mas as coisas não são bem assim. Penso que uma visão mais aprofundada do conflito entre as duas outras pares do quadrilátero de mulheres desenhado, B ibiana e L uzia, pode elucidar algo que afaste as visões maniqueístas e simplificadoras. E aqui vemos outro traço dos processos de É rico: não raro, os confrontos são também processos de espelhamento.

Do ponto de vista da fabulação, o confronto entre as duas mulheres se encaixa numa relação triangular, pois ambas são observadas sobretudo do ponto de vista do bizarro Dr. Winter. Através do olhar deste, vemos em Luzia uma gama de sinais da perversão do espírito humano. E la é "louca”, "doente”, “sádica”, tem orgasmos diante do sofrimento alheio, como no momento em que vê, da janela do Sobrado, um negro ser enforcado. Diante dela, Bibiana parece um poço de virtu- 
de, um quadro de severidade exemplar. No entanto, se a Teiniaguá dá mostras de ter dentro de si "algo", uma "alteridade" incontrolável, trazendo para o convívio das pessoas comuns a sombra do espírito humano, B ibiana concebe o maquiavélico plano de apossar-se do Sobrado através do casamento do filho. Por quê? Porque para ela o casarão, então novo e rutilante, despertando inveja até nos Amarais, se assenta sobre a "sombra" da casa de seu pai, já que esta fora demolida para dar lugar à "outra". E stivéssemos (eu e o leitor) atrás de uma interpretação freudiana, teríamos aí uma pista inequívoca de uma gama de complexos insondáveis e mal resolvidos. Além disso, Bibiana dá mostras de satisfações igualmente insondáveis. Diante da agonia de Aguinaldo Silva, o "estranho", avô de Luzia, pernambucano, que se apossara das terras e da casa de sua família, B ibiana manifesta, aos olhos do Dr. Winter, reações que lembram as de Luzia diante do negro enforcado.

Luzia: "Primeiro o rosto dela se contorceu num puxão nervoso, como se ela tivesse sentido uma dor aguda. Depois se fixou numa expressão de profundo interesse que aos poucos se foi transformando numa máscara de gozo que pareceu chegar quase ao orgasmo" ( $O$ continente, p. 384).

Bibiana: "Os olhos da mãe de B olívar brilharam com uma súbita luz de alegria que lhe iluminou o rosto inteiro por uma fração de segundo" ( $O$ continente, $p$. 396).

A diferença entre ambas é que Bibiana têm objetivos práticos mais palpáveis e menos vocação para a cena. Os espíritos, ao lado de suas inegáveis diferenças de valores e de estilos, se espelham: em ambas habita a "sombra", que se manifesta como uma espécie de prazer diante da morte. E, se Luzia leva Bolívar ao desespero, e portanto à morte, Bibiana faz o mesmo, por outros caminhos e outros objetivos. Perde o filho, fica com o neto e o Sobrado. Mas tempos depois sua trisneta vai por tudo a perder com seu frevo rasgado.

O próprio Dr. Winter, diante do drama das mulheres, e do assassinato de B olívar, confessa a sua "sombra" para seu correspondente Von Koseritz, ao escrever que no cemitério, ali mesmo diante do caixão do morto, desejou

“violenta e carnalmente Luzia Cambará" (O continente, p. 458).

Escrevera logo antes:

"tive um vislumbre da besta que dorme dentro de cada um de nós".

Sem coragem de denunciar a própria "sombra", o que afirma o seu poder, ele rasga a carta antes de mandá-la. Mas a presença da "sombra" ele vinha vislum- 
brando desde sempre, tanto na perturbada Luzia quanto na equilibrada B ibiana. E este, penso, é um dos temas preferenciais de É rico, que ele persegue tanto nos broncos ou refinados machos quanto nas quietas ou estouvadas fêmeas. Porque este é o tema que ele considera ter herdado do seu tempo - marcado pelas guerras, pelo fascismo, pelo estalinismo, como da sua história - a história do R io Grande, cuja série intermitente de guerras contínuas serve também de moldura metafórica para a ind agação de É rico sobre a natureza da "besta" humana e portanto pela própria natureza humana.

Aqui, para encerrar, é necessário acrescentar um comentário sobre o próprio romance e mais uma personagem: Maria Valéria. De certo modo, ela ocuparia, neste encurvar-se do tempo que É rico provoca, o centro ${ }^{4}$ daquele quadrilátero de mulheres. M aria Valéria não tem filhos; mas é abrindo o seu baú de guardados e de histórias (V. O arqui pélago, p. 748) que F loriano vai buscar a inspiração para o seu romance. Portanto são eles dois - o escritor e a vestal da memória - os genitores da obra. O romance torna-se um espaço de conjuração daquela "besta" que parece à solta em toda a parte, em todos os tempos. Se Érico depõe sobre a violência, é para conjurá-la. Afinal, além de liberal, era um humanista. E um humanista algo cruel com as fragilidades dos seus homens. Mas fiel à força das suas mulheres.

4 Ouvi do Prof. Antonio Dimas, de Literatura Brasileira da USP, a interessante sugestão de que Maria Valéria ocuparia mesmo o centro de todo $O$ tempo e o vento. 